\title{
Cable Insulation Failure Probability Analysis in Nuclear Power Plant Distribution Cabinet Fire
}

\author{
Qiang $\mathrm{Li}^{1}$, Jia-qing Zhang ${ }^{2}$, Jin-mei $\mathrm{Li}^{1,3}$ and Shi-jing $\mathrm{Ren}^{1}$ \\ ${ }^{1}$ Chinese People's Armed Police Academy, Department of Fire Protection Engineering, 065000 Langfang, China \\ ${ }^{2}$ State Grid Anhui Electric Power Research Institute, 230022 Hefei, China \\ ${ }^{3}$ University of Science and Technology Beijing, School of Civil and Resource Engineering, 100083 Beijing, China
}

\begin{abstract}
This paper takes the nuclear power plant power distribution cabinet fire as example and adopts FPRA methodology to analyse the failure probability of cable insulation at contiguous region among distribution cabinet. The influential factor that fire brigade dealt with the fire in the spot is considered in this research. The cumulative distribution function of fire brigade's arriving and extinguishing time is conducted discretization, confirming the sample statistics of areas and establishing the numbers of cable insulation failure events of distribution cabinet fire. Combining failure predicted model of cable insulation and calculating the failure situation of cable insulation under each of fire background, obtaining the probability that cable insulation failure events among the distribution cabinet fires. The results show that the $\mathrm{HRR}_{\max }$ of distribution cabinet fire in term of case scenario is $750 \mathrm{~kW}$, the cable never happens the insulation failure; when the distribution cabinet fire is $1000 \mathrm{~kW}$, the possibility of cable insulation failure is $12.6 \%$.
\end{abstract}

\section{Introduction}

Fire is one of the most direct and significant threats to nuclear power plant [1]. As one of the effective ways to evaluate and avoid fire risk in nuclear power plant, fire probabilistic risk assessment (PRA) has provided great safeguard against fire for active and newly-built nuclear power plants in China, which leads them to functioning safely [2].

The foundation for fire probabilistic risk assessment is to analyse the probability of fire by researching on the failure probability of each system functional component when there is a fire. As the pulse and nerve for nuclear power plant functioning, cable is the potential risk for disaster expanding as the insulating failure is likely to occur under the influence of high ambient temperature and intense radiation heat flux in a fire, which may consequently lead to the disability of electricity transportation and information spread. Therefore, the probability of cable insulating failure is one of the main topics in fire probabilistic risk assessment for nuclear power plant.

According to statistics, internal fire is the main disaster form for nuclear power plant to suffer from considerable economic loss and social impact [3], in which distribution cabinet fire is the most common sort. As the centre of power and essential power distribution unit, distribution cabinet is often installed in where cable is concentrated such as transformer substation and distribution room. Once the distribution cabinet is in fire, it is a direct threat to electric circuit in contiguous region.

\section{Probability distributions distribution cabinet fire scenes}

\subsection{Time distributions of fire brigade arrival and fire put-out}

According to the statistics provided by NUREG/CR6850 [4], when there is a fire in nuclear power plant, the time of fire brigade arrival can be described by the normal distribution function $N(11.25,1.875)$. Therefore, to integrate this function, we can obtain the accumulated distribution function of the fire brigade processing time, which is the probability distribution of the fire brigade processing time, and it is showed in Fig. 1.

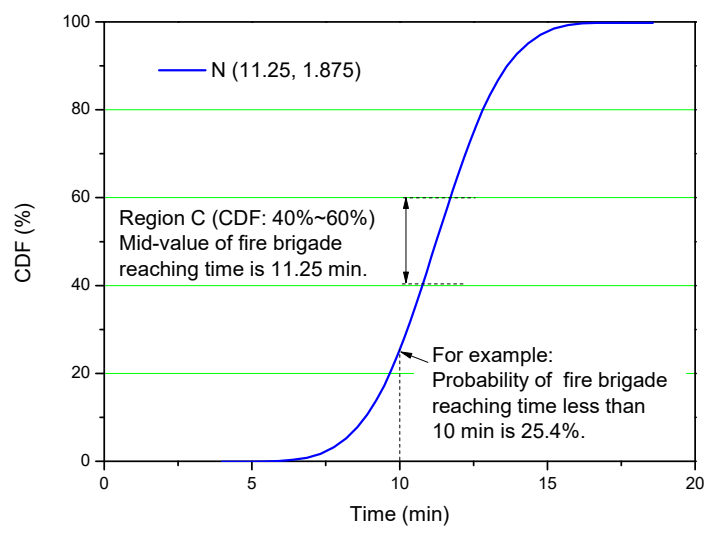

Fig. 1. Cumulative distribution function of fire brigade reaching time. 
The success probability of fire brigade processing the fire scene $(P)$ and the required time of fire fighting is an exponential function [4]:

$$
P=1-e^{-\lambda t}
$$

Where $t$ is the required time of fire fighting, $\min ; \lambda$ is frequency index, for distribution cabinet fire, cable fire and other electric fire, this index is 0.120 [3]. Therefore, we can obtain the accumulated distribution function of the required time of fire brigade arrival and fire fighting, as is showed in Fig. 2.

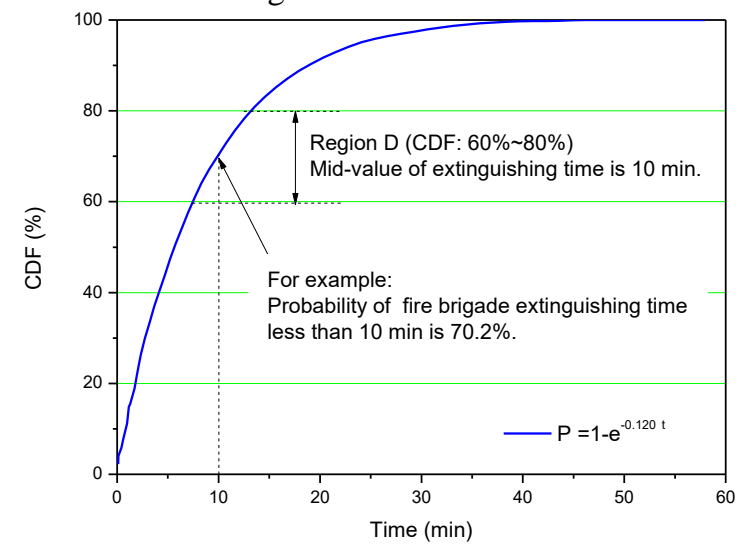

Fig. 2. Cumulative distribution function of fire brigade extinguishing time.

\subsection{Discrete probability distributions}

Heat Release Rate (HRR) is an important fire-property index to describe the fire scene. We can divide the probable fire scene according to HRR-Time curve. Fig. 2 is the curve of HRR-Time in a fire, in which "(A)" scene describes that fire brigade arrives before the maximum heat release rate occurs $\left(\mathrm{HRR}_{\max }\right)$ and is successfully put out later; "(B)" scene describes that fire brigade arrives after the maximum heat release rate occurs $\left(\mathrm{HRR}_{\max }\right)$ and is successfully put out soon; as the same scene which describes that fire brigade arrives after the maximum heat release rate occurs $\left(\mathrm{HRR}_{\max }\right)$, the "(C)" scene fire fighting process is not ideal, and takes a long time to put out; and in "(D)" scene, fire is merely unnoticed and continues steadily after reaching $\mathrm{HRR}_{\max }$.

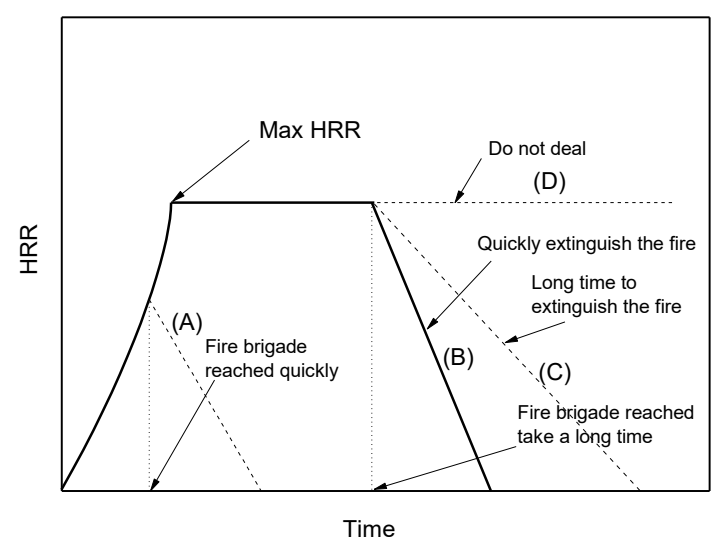

Fig. 3. Sketch map of HRR-time curve in fire.
It can be observed that the HRR-Time curve that describes distribution cabinet fire scene is related to the curve of fire brigade processing time and fire extinguishing time. That is, the number of fire scenes is product of the fire brigade reaching scenes and the fire brigade extinguishing scenes.

To simplify the latter analysis for cable insulating failure probability, and randomize the accumulated distribution function of the fire brigade arrival time and fire fighting time, we divide the accumulated probability of the problem we work on into 5 equal-probability regions and choose sample index as regional sample value according to regional mid-value, and therefore, the regional sample value of fire brigade arrival time and fire fighting time is showed in Table 1.

Table 1. The sample data scene region.

\begin{tabular}{|c|c|r|r|}
\hline $\begin{array}{c}\text { Region } \\
\text { Number }\end{array}$ & $\begin{array}{c}\text { CDF } \\
(\boldsymbol{\%})\end{array}$ & $\begin{array}{c}\text { Time of Fire } \\
\text { Brigade Arrival } \\
\text { (min) }\end{array}$ & $\begin{array}{c}\text { Time of Fire } \\
\text { Put-out (min) }\end{array}$ \\
\hline A & $0 \sim 20$ & 8.90 & 0.90 \\
\hline B & $20 \sim 40$ & 10.30 & 3.00 \\
\hline C & $40 \sim 60$ & 11.25 & 5.80 \\
\hline D & $60 \sim 80$ & 12.20 & 10.00 \\
\hline E & $80 \sim 100$ & 13.70 & 19.20 \\
\hline
\end{tabular}

According to the scene division approach showed in Table 1, when taking the effect from the fire brigade arrival time and fire fighting time on the fire development principle into account, we can obtain 25 equal-probability distribution cabinet fire scene in nuclear power plant under the effect of fire brigade processing. In this article, we choose two regional serial number to describe the distribution cabinet fire scene in nuclear power plant, such as "BC" represents the probability of fire brigade arrival time is in Region " $\mathrm{B}$ ", and the probability of fire fighting time is in Region " $\mathrm{C}$ ".

\section{Temperature change in fire scenes}

\subsection{Fire simulation scene}

Research shows that the main cause for cable insulating failure is the internal destruction inside the cable from the high fire temperature. Therefore, we should analyse the cable insulating failure situation according the temperature change in the fire scene.

This article uses FDS fire simulation approach, and obtain the ambient temperature change process in each fire scene of distribution cabinet fire in nuclear power plant. The research scene is a small distribution room on a regular nuclear power plant island. As is showed in Fig. 4 , the distribution room is a cuboid room with its internal size of $9.8 \mathrm{~m}(\mathrm{~L}) \times 4.8 \mathrm{~m}(\mathrm{~W}) \times 3 \mathrm{~m}(\mathrm{H})$. In the middle and one broadside of the distribution room installed 2 rows of distribution cabinet. And in the other boardside of the distribution room installed 7 layers of cable bridge. The division between is $0.2 \mathrm{~m}$. Above the cable bridge installed a row of overhead cable. In the shorter boardside of the distribution room is an open door of 1.5 
$\mathrm{m}(\mathrm{W}) \times 2.3 \mathrm{~m} \quad(\mathrm{H})$. There is no automatic fireextinguishing facilities in the distribution room.

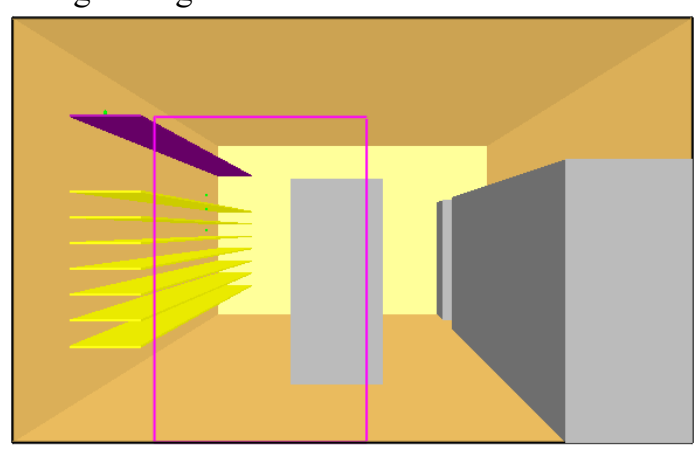

(a) front view

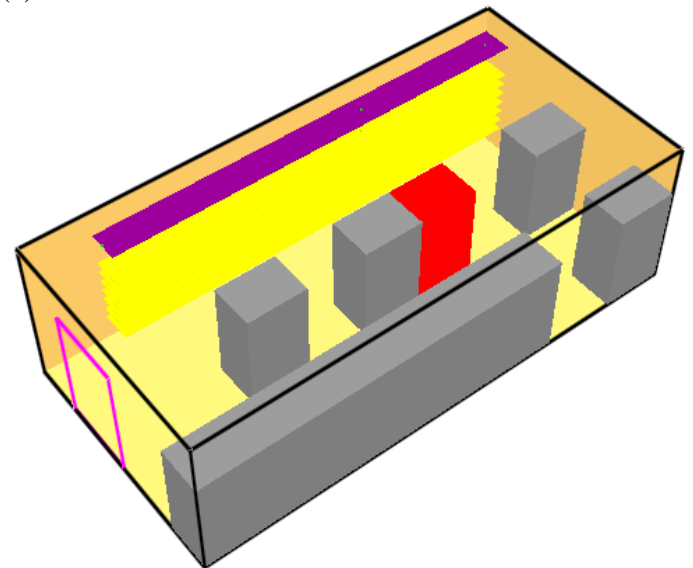

(b) top view

Fig. 4. Scene of fire simulation.

As is showed in Fig. 4(b), in the research, one distribution cabinet in the middle of the simulation distribution room runs out of control and turns into fire. The distribution cabinet fire is the $t$-square fire in Fig. 3, with its fire increasing modulus $(\alpha) 0.0469$ [3], $\mathrm{HRR}_{\max }$ $750 \mathrm{~kW}$ and $1000 \mathrm{~kW}$. The cable is in the single row of cable which is above the cable bridge and overhead. In this fire condition, the cable is surrounded by an air of smoke. Near the tested cable set a temperature measure point, used to measure the ambient temperature of the cable in the development of fire.

\subsection{Ambient temperature in fire scenes}

The ambient temperatures of the cable in the process of nuclear power plant distribution cabinet fire scenes are showed in Fig. 5.

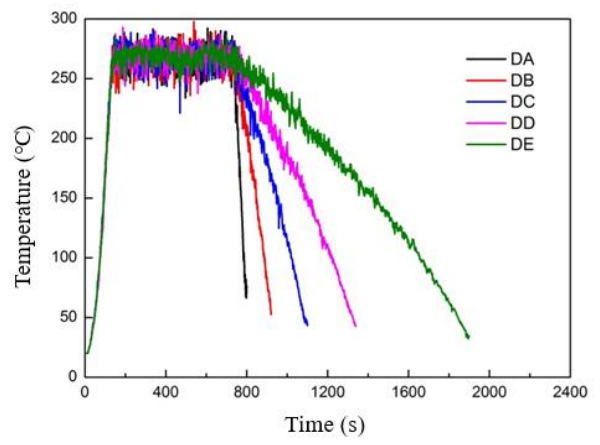

(a) fire scene DA DE $\left(\mathrm{HRR}_{\max }=750 \mathrm{~kW}\right)$

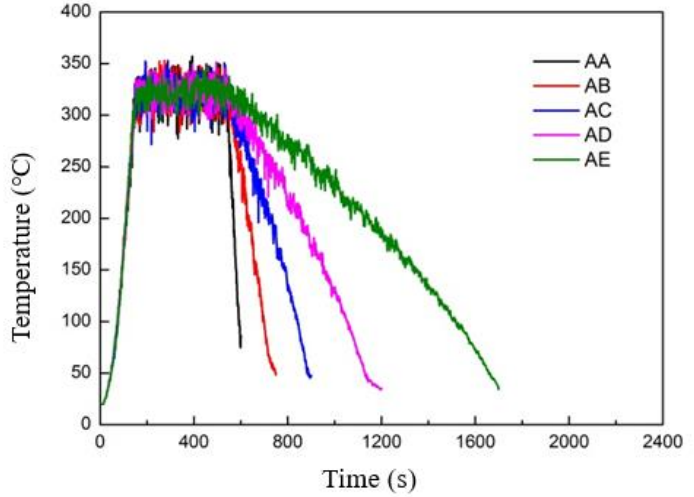

(b) fire scene $\mathrm{AA} \sim \mathrm{AE}\left(\mathrm{HRR}_{\max }=1000 \mathrm{~kW}\right)$

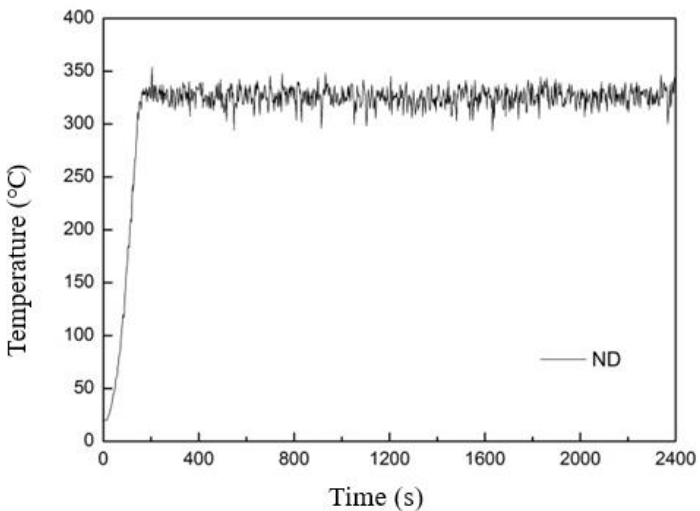

(c) not dealing with fire $\left(\mathrm{HRR}_{\max }=1000 \mathrm{~kW}\right)$

Fig. 5. Ambient temperature in different fire scenes (partial data).

\section{Determination of insulating failure temperature of nuclear cable}

\subsection{Cable heat radiation test oven and experimental design}

The research shows that the cable insulating failure can be predicted according to the temperature of failure point. In this research, the test cable is 1E-Class K3-Type 300/500V WDZ-HK3-PYJP3YJP which is used in nuclear power plant. Its thermal physical property index is showed in Table 2.

Table 2. Thermophysical parameters of WDZ-HK3PYJP3YJP3.

\begin{tabular}{|l|c|c|}
\hline $\begin{array}{c}\text { Cable } \\
\text { Structure }\end{array}$ & $\begin{array}{c}\text { Heat-conducting } \\
\text { medium }\end{array}$ & $\begin{array}{c}\text { Heat Diffusion } \\
\text { Coefficient }\left(\mathbf{m}^{2} / \mathbf{s}\right)\end{array}$ \\
\hline Copper core & Copper & $1.16 \times 10^{-4}$ \\
\hline Insulating layer & $\begin{array}{c}\text { Crosslinked } \\
\text { polyethylene }\end{array}$ & $1.52 \times 10^{-7}$ \\
\hline Mixed layer & $\begin{array}{c}\text { Filled Material and } \\
\text { Shield-Protecting } \\
\text { Material }\end{array}$ & $1.50 \times 10^{-7}$ \\
\hline
\end{tabular}

The ambient temperature and radiation surrounding is simulated by SDR-1Type cable heat radiation test oven, as is showed in Fig. 6. The highest rated output 
power is $60 \mathrm{~kW}$. Different fire scenes can be simulated by setting radiation output power in the oven through controlling equipment. The test scenes in this research are showed in Table 3.

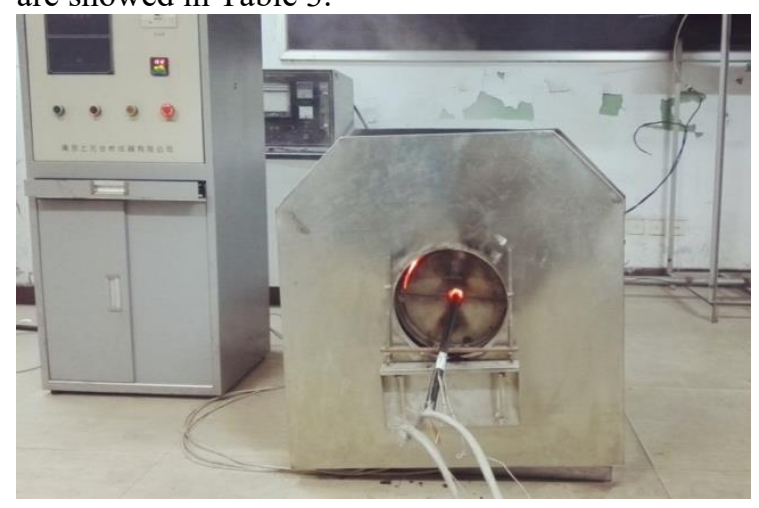

Fig. 6. SDR-1 cable thermal radiation experimental furnace.

Table 3. Experimental result of WDZ-HK3-PYJP3YJP3.

\begin{tabular}{|c|c|c|}
\hline $\begin{array}{c}\text { Radiation } \\
\text { Heat flux } \\
\left(\mathbf{k W} / \mathbf{m}^{\mathbf{2}}\right)\end{array}$ & $\begin{array}{c}\text { Insulating } \\
\text { Failure Time } \\
(\mathbf{s})\end{array}$ & $\begin{array}{c}\text { Insulating Failure } \\
\text { Temperature } \\
\left({ }^{\circ} \mathbf{C}\right)\end{array}$ \\
\hline 3.0 & 1142 & 218 \\
\hline 4.2 & 727 & 194 \\
\hline 4.8 & 647 & 218 \\
\hline 5.4 & 644 & 213 \\
\hline 6.0 & 475 & 203 \\
\hline 9.0 & 416 & 190 \\
\hline 15.0 & 383 & 186 \\
\hline
\end{tabular}

We chose TH2683A-Type insulating resistance tester to measure the insulating resistance between the cables. In the experiment, the output of the testing side was DC1000 V. The temperature in the oven chamber and the cable failure temperature is measured by a K-Type sheathed thermocouple with its $1 \mathrm{~mm}$ diameter. A RIGOL M300-Type data collector is employed to collect the data. The processing method of the test cable is showed in Reference [6]. The judging standard for cable insulating failure is showed in Reference [7].

\subsection{Experimental Results}

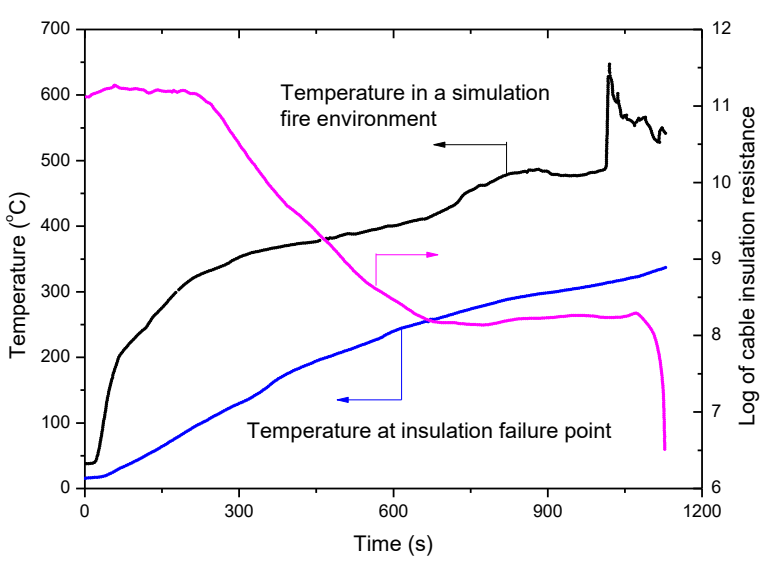

Fig. 7. SDR-1 cable thermal radiation experimental furnace.

Fig. 7 shows that under the condition of steady radiation heat flux the typical change curve of oven chamber temperature, cable insulating failure temperature and insulating resistance.

By recording the cable insulating failure time, the cable insulating temperature in each condition is showed in Table 3.

\subsection{Average insulating failure temperature}

Fig. 8 is the cable insulating failure temperature in each test condition. It can be observed that the ambient radiation heat flux had little effect on the cable insulating failure temperature. The lowest insulating failure temperature is $186^{\circ} \mathrm{C}$ and the highest is $218^{\circ} \mathrm{C}$.

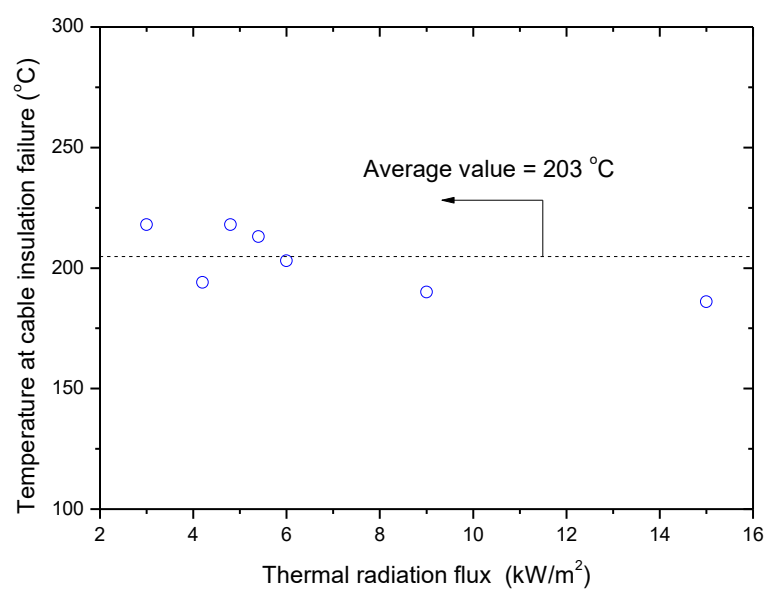

Fig. 8. Insulation failure temperature of DZ-HK3-PYJP3YJP3 under different external thermal flux situations.

The research showed, the same insulating material shared mainly the same insulating temperature [7]. Therefore, when calculating the predicted model, the judging standard for cable insulating failure is the average insulating failure temperature measured by the test that was $203^{\circ} \mathrm{C}$.

\section{The cable insulating failure probability analysis in the distribution cabinet}

\subsection{Prediction model of cable insulating failure in fire and calculated results}

Reference [8] establishes the heat-transmission differential equation used to predict the temperature change in the cable:

$$
\rho c \frac{\partial T}{\partial t}=\frac{1}{r} \frac{\partial}{\partial r}\left(k r \frac{\partial T}{\partial r}\right)
$$

Where $r$ is the distance along the cable cross section from the circle centre, $\mathrm{mm} ; T$ is the temperature along the cable cross section $r$ away from the circle centre, ${ }^{\circ} \mathrm{C}$; $t$ is time, $\mathrm{s} ; \rho$ is the density of the material, $\mathrm{kg} / \mathrm{m}^{3} ; \mathrm{c}$ is the specific heat, $\mathrm{J} /(\mathrm{kg} \cdot \mathrm{K}) ; \mathrm{k}$ is the thermal conductivity of the material, $\mathrm{W} /(\mathrm{m} \cdot \mathrm{K})$.

WDZ-HK3-PYJP3YJP3 cable thermal physical index is list in Table 2, and we employ Eq. (2) to calculate and obtain the change principle of cable insulating failure 
temperature and time. Then combined with the WDZHK3-PYJP3YJP3 cable insulating failure temperature $\left(203{ }^{\circ} \mathrm{C}\right)$, predict the cable insulating failure situation in each fire scene.

The result showed, on condition of $\mathrm{HRR}_{\max } 750 \mathrm{~kW}$, even without participation of fire brigade the cable is unlikely to insultingly fail. But on condition of $\mathrm{HRR}_{\max }$ $1000 \mathrm{~kW}$, the cable insulating failure situation in each fire scene is showed in Table 4, in which "CF" stands for insulating failure occurred and "OK" stands for the opposite.

Table 4. Result of cable insulation failure $(q=1000 \mathrm{~kW})$.

\begin{tabular}{|c|c|c|c|c|c|}
\hline $\begin{array}{c}\text { Region Number of } \\
\text { Time of Fire Brigade } \\
\begin{array}{c}\text { Arrival } \\
\text { (First letter) }\end{array}\end{array}$ & \multicolumn{5}{|c|}{$\begin{array}{c}\text { Region Number of Fire Brigade } \\
\text { Extinguishing Time } \\
\text { (Second letter) }\end{array}$} \\
\cline { 2 - 6 } & A & B & C & D & E \\
\hline A & OK & OK & OK & OK & OK \\
\hline B & OK & OK & OK & OK & OK \\
\hline C & OK & OK & OK & OK & OK \\
\hline D & OK & OK & OK & OK & CF \\
\hline E & OK & OK & OK & OK & CF \\
\hline
\end{tabular}

\subsection{The cable insulating failure possibility in fire based on the event tree analysis}

We establish the distribution cabinet fire cable insulating failure event tree as Fig. 9.

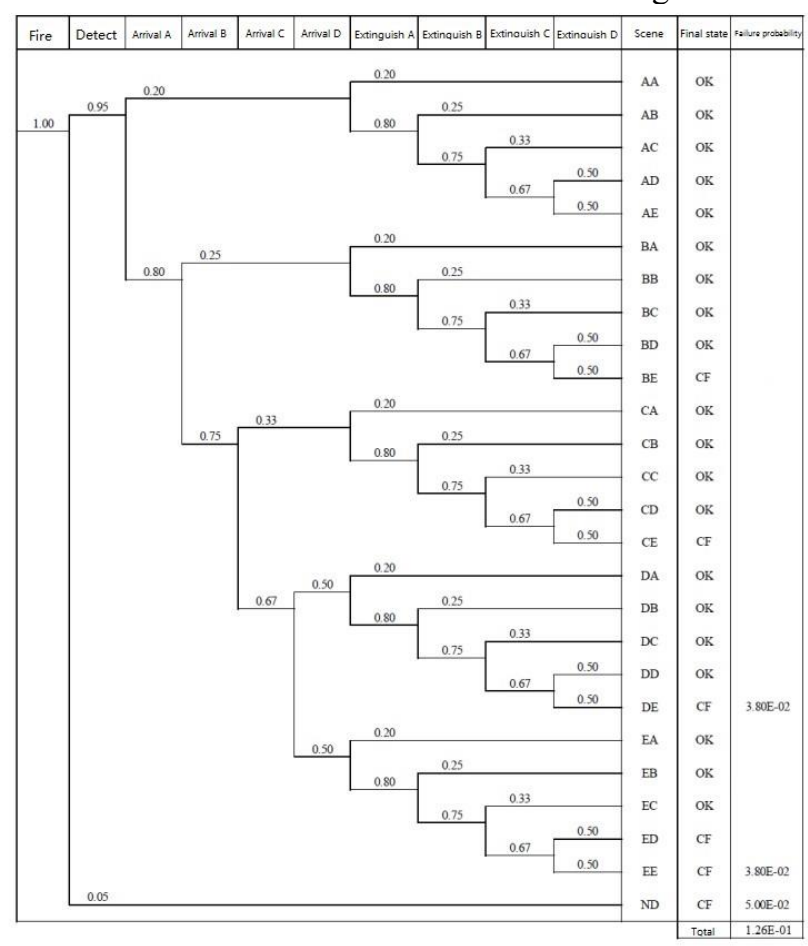

Fig. 9. Event tree analysis of cable insulation failure in nuclear power plant distribution cabinet fires

In the regular distribution room of the nuclear power plant installed the fire detection equipment. In the analysis, the probability of fire detection equipment failing to respond, which leads to the loss of fire brigade is $5 \%$. According to the fire scene division approach in Table 1, the subevent of fire brigade processing the fire scene is probable equally. Therefore, by calculation we can obtain the 26 fire scenes' probability.

On condition of $\mathrm{HRR}_{\max } 750 \mathrm{~kW}$, as the cable insulating failure occurs in no fire scene, the cable insulating failure probability caused by fire is 0 . For fire scene with $\mathrm{HRR}_{\max } 1000 \mathrm{~kW}$, combined with the cable insulating failure situation in all fire scenes in Table 4, we can calculate the cable insulating failure probability in distribution room fire is $12.6 \%$.

\section{Conclusion}

This article takes the fire of distribution cabinet in nuclear power plant as an example, comes up with analysis approach of the cable insulating failure probability of the distribution cabinet fire in contiguous regions. Firstly, by introducing the effect from the fire brigade on the development of fire, it set the probability distribution of distribution cabinet fire under fire brigade processing. Subsequently, by conducting the nuclear cable insulating failure experiment in fire, FDS fire simulation, and it obtained fire scene ambient temperature. By analyzing predicted cable insulating failure model, it calculated the cable insulating failure situation in each fire scene. Ultimately, by establishing the event tree of distribution cabinet, it calculated the cable insulating failure probability is $12.6 \%$ when $\mathrm{HRR}_{\max }$ is $1000 \mathrm{~kW}$.

\section{References}

1. Bucknor M.D., Modeling of electrical cable failure in a dynamic assessment of fire risk, The Ohio State University, U.S., (2013)

2. Cha E.J., Elligwood B.R. Structural Safety 44 (2013)

3. Baranowsky P., Facemire J.W., The updated fire events database: description of content and fire event classification guidance, Electric Power Research Institute, Palo Alto, CA (2013)

4. Kassawara R.P., Hyslop J.S., NUREG/CR-6850 (2005)

5. Wang G., Experimental study on the effect of fire retardant coating for insulation failure of cable, Langfang, The Chinese People's Armed Police Academy (2011)

6. Yang Y.C., Li Q., Zhang J.Q., and Fan M.H., Procedia Engineering 135 (2016)

7. Nowlen S.P., Wyant F.J., NUREG/CR-6931 2 (2008)

8. Ren S.J., Research on the prediction model of fireinduced electrical cable failure in nuclear power plants, Langfang, The Chinese People's Armed Police Academy (2016) 